REVIEW

\title{
Pathogenesis and treatment of Clostridium difficile infection
}

\author{
I Tonna, P D Welsby
}

Postgrad Med J 2005;81:367-369. doi: 10.1136/pgmj.2004.028480

This paper reviews the pathogenesis and management of Clostridium difficile diarrhoea, in particular the management of recurrent episodes.

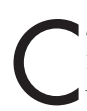

lostridium difficile is a Gram positive, spore forming anaerobic bacillus that in contrast

with popular belief is not a normal commensal of the adult gastrointestinal tract. ${ }^{1}$ The organism is acquired from an exogenous source and given certain conditions can induce disease. Consequences range from asymptomatic carriage, dehydration, metabolic changes, bowel perforation, and haemorrhage. The mortality is highest in the elderly population and is about $1.5 \%$ of all hospitalised cases of $C$ difficile diarrhoea. ${ }^{2}$ There are five major patterns of $C$ difficile induced disease (see table 1).

\section{PATHOGENESIS}

There are two prerequisites for developing $C$ difficile associated diarrhoea: disruption of the normal gastrointestinal flora, causing diminished colonisation resistance favouring $C$ difficile, and acquisition of the organism from an exogenous source. Other factors include host susceptibility, virulence of the $C$ difficile strain concerned, and the nature and extent of antimicrobial exposure. ${ }^{3}$

In normal people there are more than 500 species of bacteria in the colon. A gram of faeces normally contains up to $10^{12}$ bacteria that resist colonisation and impair multiplication of $C$ difficile. Lactobacilli and group $\mathrm{D}$ enterococci display most antagonistic activity, ${ }^{8}$ and eradication or reduction of such bacteria by antibiotics creates an environmental vacuum for $C$ difficile to fill. People have significant variations in their intestinal microflora and the elderly population are most at risk of $C$ difficile diarrhoea, possibly because their protective bacteroides diversity is more likely to be affected by antibiotics, which then permit growth of $C$ difficile. ${ }^{4}$

There are more than 400 strains of $C$ difficile. Infection is acquired faeco-orally and $C$ difficile multiplies in the colon. Only toxin producing strains produce disease. ${ }^{10}$ Toxins are endocytosed by colonic epithelial cells and damage the actin cytoskeleton, causing cell death. There are two toxins that together are normally required to cause $C$ difficile associated diarrhoea. Toxin A disrupts colonic mucosal cell adherence to colonic basement membrane and damages villous tips. Toxin B enters the cell by endocytosis and induces apoptosis. Toxin B is 1000 times more potent in its cytotoxic effect than toxin A. Both toxins stimulate monocytes and macrophages, which in turn release interleukin 8, resulting in tissue infiltration with neutrophils. ${ }^{11}$
However, infection with "virulent" strains of toxin producing $C$ difficile can be asymptomatic implying that other factors, including the environment within the gut are important. ${ }^{12-15}$

The extent of clinical manifestations depends on the immune response to $C$ difficile. Patients with low anti-toxin A IgG levels manifest more severe disease unlike those with higher levels who usually recover spontaneously. ${ }^{5}$

\section{TREATMENT}

In mild cases, oral rehydration plus withdrawal of the causative antibiotic is often successful. ${ }^{16}$ Identification of $C$ difficile or its toxins should not lead to reflex prescription of metronidazole or vancomycin. Oral rehydration alone may succeed because it allows host immunological responses to deal with the infection and does not create additional ecological vacuums for $C$ difficile to reemerge into once metronidazole or vancomycin is stopped. Oral metronidazole or vancomycin can be used if symptoms are severe. Metronidazole is preferred because it is less expensive, well tolerated when given for short periods, is effective as vancomycin, and does not encourage vancomycin resistant enterococci. ${ }^{17}$ Parenteral antibiotic therapy is less effective than the oral route. Intravenous metronidazole is of dubious efficacy. Although there were case reports of some clinical benefit when used in patients in whom oral administration was impractical, further trials are needed to assess the effectiveness of intravenous compared with oral metronidazole. ${ }^{18}$ Vancomycin is not excreted into or absorbed from the gastrointestinal lumen. Consequently, parenteral administration of the drug will not reach the site of infection. Nasogastric tube or enema administration may be necessary. ${ }^{5619}$

There are two main reasons for recurrences after successful treatment with metronidazole or vancomycin:

(1) Neither antibiotic eliminates $C$ difficile spores. Once metronidazole or vancomycin are stopped spores will germinate and $C$ difficile will proliferate in the ecological vacuum with return of diarrhoea. ${ }^{20}$

(2) Administration of any antibiotic may induce expression of $C$ difficile virulence factors that will be most developed just before the antibiotic is stopped. Hence, diarrhoea will recur after the treatment is stopped. It is known that toxin production occurs after the end of the exponential growth phase, whereas much lower levels are seen in early and midexponential growth phase. ${ }^{21}$ In such situations, the relapse would be expected to occur soon after stopping metronidazole or vancomycin or even during the course of treatment. 
Table 1 Clinical range of Clostridium difficile infections ${ }^{7}$

\begin{tabular}{|c|c|}
\hline Infection pattern & Characteristics \\
\hline \multirow[t]{2}{*}{$\begin{array}{l}\text { Asymptomatic carriage (up to } 5 \% \text { of healthy adults, } \\
20 \% \text { in patients hospitalised for one week, } \\
50 \% \text { in patients hospitalised for four weeks) }\end{array}$} & $\begin{array}{l}\text { Most common occurrence, the infected person } \\
\text { acts as a reservoir of infection }\end{array}$ \\
\hline & $\begin{array}{l}\text { Possibility of dissemination of organisms within } \\
\text { hospital environments } \\
\text { No systemic symptoms }\end{array}$ \\
\hline \multirow[t]{2}{*}{$\begin{array}{l}\text { "Simple" antibiotic associated diarrhoea } \\
\text { (20\% of all cases with presumed } \\
\text { antibiotic associated diarrhoea] }\end{array}$} & $\begin{array}{l}\text { Common during treatment with antibiotics } \\
\text { Diarrhoea usually stops after the antibiotic is } \\
\text { withdrawn }\end{array}$ \\
\hline & $\begin{array}{l}\text { Mild oedema and hyperaemia of the rectum on } \\
\text { sigmoidoscopy, but with normal colonic mucosa }\end{array}$ \\
\hline $\begin{array}{l}\text { Diarrhoea without pseudomembrane formation } \\
(20 \% \text { have proximal disease undetected on } \\
\text { routine flexible sigmoidoscopy })^{5}\end{array}$ & $\begin{array}{l}\text { Systemic manifestations including low grade } \\
\text { fever and leucocytosis } \\
\text { Abdominal pain } \\
\text { Endoscopically there may be patchy } \\
\text { erythematous colitis }\end{array}$ \\
\hline $\begin{array}{l}\text { Pseudomembranous enterocolitis ( } 10 \% \text { of } C \\
\text { difficile associated diarrhoea) } \\
\text { Fulminant colitis ( } 3 \% \text { of } C \text { difficile associated diarrhoea) })^{6}\end{array}$ & $\begin{array}{l}\text { Typical elevated yellowish plaques on } \\
\text { colonoscopy } \\
\text { High risk of complications such as perforation, } \\
\text { megacolon, or death }\end{array}$ \\
\hline
\end{tabular}

Recurrence rates of $C$ difficile diarrhoea vary between $15 \%$ to $35 \%$ but may be as high as $55 \% .^{22-24}$ Most relapses occur within two months. ${ }^{22}$ Recurrences can occur when original strains re-establish themselves or if infection with a different strain of $C$ difficile occurs.

\section{TREATMENT OF SYMPTOMATIC RELAPSES OF CLOSTRIDIUM DIFFICILE ASSOCIATED DIARRHOEA}

Symptomatic return occurs when diarrhoea reappears along with positive tests for $C$ difficile toxin in the faeces. The diagnosis is made when $C$ difficile toxin is identified in the stools. The presence of the organism in the stool does not necessarily mean that the diarrhoea is attributable to $C$ difficile.

There are a number of options for treating relapses of $C$ difficile diarrhoea:

(1) If diarrhoea is mild, simple supportive treatment is advocated to allow the intestinal flora to stabilise, allowing the diarrhoea to settle. ${ }^{16}$

(2) If diarrhoea is severe, another course of oral metronidazole or vancomycin should be given. ${ }^{16}$

(3) There are 10 other options to be considered in problematical relapses (box).

Further courses of metronidazole or vancomycin have been administered either as:

- A prolonged repeat of treatment for 10-16 days. ${ }^{20}$ High dose vancomycin ( $2 \mathrm{~g} /$ day $)$ was associated with a lesser rate of

\section{Treatment options of severe relapses}

- Tapering doses of vancomycin ${ }^{20}$

- Pulsed regimen of vancomycin ${ }^{20}$

- Use of colestyramine ${ }^{25}$

- Use of probiotics ${ }^{26-29}$

- Combined use of probiotics with high dose vancomy$\operatorname{cin}^{29}$

- Intravenous gammaglobulin administration ${ }^{31-34}$

- Faecal enemas ${ }^{35}$

- Whole gut lavage ${ }^{36}$

- Stool administered via colonoscope after whole gut lavage ${ }^{35}$ recurrence of diarrhoea than medium/low dose vancomycin ( $44 \%$ v $71 \%-54 \%$ ). Medium dose metronidazole ( 1.5 g/day) had a recurrence rate of $40 \%$ whereas it was $44 \%$ with the low dose form $(<1 \mathrm{~g} /$ day $)$. The number of patients treated with high dose metronidazole $(\mathrm{n}=2)$ did not have sufficient power to reach statistical significance.

- A tapering regimen with metronidazole or vancomycin started at a high dose ( $>2 \mathrm{~g} /$ day of vancomycin or $2 \mathrm{~g} /$ day of metronidazole). ${ }^{20}$ The vancomycin dose was decreased over 10-30 days to a dose of 125 to $750 \mathrm{mg}$ /day depending on the preference of the physician. The best response was found in those cases given a starting dose of vancomycin $500 \mathrm{mg}$ /day tapering to $125 \mathrm{mg}$ /day over three weeks. This was associated with a $20 \%$ recurrence of diarrhoea. The number of patients treated with tapering doses of metronidazole $(\mathrm{n}=1)$ was too low to be commented upon.

- A pulsed regimen. ${ }^{20}$ Vancomycin was given in pulsed 125$500 \mathrm{mg}$ doses every three days for three weeks (dose being determined by the responsible physician). When the $500 \mathrm{mg}$ pulse was used this was associated with the lowest recurrence rate of diarrhoea (14\%). Only one patient was given pulsed metronidazole, thus no clinically significant data could be extrapolated.

- A combination of the above. ${ }^{20}$ Some of the patients were first treated with a tapering regimen of vancomycin followed by short courses of pulsed doses for 3-10 days. The recurrence rate was $20 \%$.

The best results were seen when pulsed regimens were used. Pulsed regimens may be superior because they allow spores to germinate during the antibiotic free period with the resulting $C$ difficile being killed by the next pulse and allowing the normal colonic flora to re-establish itself during the pulse free period. ${ }^{20}$

Colestyramine binds $C$ difficile toxin but is of unproved clinical benefit and therefore cannot be recommended. ${ }^{25}$

Oral probiotic therapy (use of live non-pathogenic bacteria to "restabilise the gut flora" and provide colonisation resistance against $C$ difficile) uses organisms resistant to gastric acid. Lactobacillus acidophilus and Saccharomyces boulardii produce proteases that digest $C$ difficile toxins. ${ }^{26}$ The initial trial used known quantities of $S$ boulardii. Use of probiotic yoghurts with similar organisms (for example, $S$ cerevisiae) may not have the same effect. ${ }^{28}$ The optimum dose of any probiotic is unknown, but a study using $1 \mathrm{~g} /$ day of $S$ boulardii with $2 \mathrm{~g} /$ day vancomycin for 28 days was found to be $67 \%$ more effective than 
vancomycin alone. ${ }^{29}$ Probiotics are attractive therapeutic options because they are inexpensive, are palatable, and rarely cause harm except perhaps in the immunocompromised. ${ }^{30}$

It is possible that patients who develop relapses are a subgroup of those infected who are slow to mount immunoglobulin responses, especially those treated early with vancomycin or metronidazole. The larger the immunoglobulin response to $C$ difficile toxin A during initial episodes of diarrhoea, the lower the rates of recurrent diarrhoea. Patients with low levels of immunoglobulin G to toxin A had a 48 -fold increase in risk of relapse. Passive immunisation against $C$ difficile might be possible because normal pooled human immunoglobulin preparations contain significant titres of $C$ difficile antitoxins. Five children were treated successfully with intravenous immunoglobulin, ${ }^{32}$ and adult successes have also been reported..$^{33}$

Although aesthetically unpleasant, $C$ difficile diarrhoea can be treated by introducing normal intestinal flora in faeces from healthy persons via a colonoscope after whole gut lavage or even via a nasogastric tube..$^{35-37}$

\section{CAN C DIFFICILE DIARRHOEA BE PREVENTED?}

Prevention entails:

(1) avoiding exposure to $C$ difficile and its spores

(2) avoiding the use of unnecessary antibiotics

(3) supporting the immune system to deal with $C$ difficile or its toxins

$C$ difficile spores can survive up to five months in the environment and transmission often occurs in hospitals where $C$ difficile infected patients are close to susceptible patients. ${ }^{6}$ Transmission occurs via the hands of healthcare personnel. Hand washing, glove use, and appropriate isolation of those infected are important. ${ }^{3}$

Antibiotics should be given only when indicated and should be avoided if possible for the two months after successful treatment of $C$ difficile diarrhoea. ${ }^{16}$ Although the number of clinical trials are small, there is evidence that administration of probiotics may prevent antibiotic associated diarrhoea when given together with antibiotics. ${ }^{38}$ On the other hand, use of these live organisms to treat antibiotic associated diarrhoea remains to be proved.

Anti-toxin A IgG induced by vaccination was protective in hamsters $^{39}$ and a $C$ difficile toxoid vaccine resulted in high toxin A IgG in humans after four intramuscular doses. ${ }^{40}$ Whether such antibody responses confer immunity against symptomatic $C$ difficile diarrhoea, particularly in the elderly population, is unknown. Even if a vaccine were available, to whom should it be given? Should it be given to all elderly patients (and if so what is the cut off age?), to all patients after a first episode of $C$ difficile diarrhoea, or to the whole population? Cost effectiveness would need to be considered.

\section{Authors' affiliations \\ I Tonna, P D Welsby, Infectious Diseases Unit, Western General Hospital, Edinburgh, UK}

\section{REFERENCES}

1 Riley TV, Wetherall F, Bowman J, et al. Diarhoeal disease due to Clostridium difficile in general practice. Pathology $1991 ; 23: 346-9$.

2 Miller MA, Hyland M, Ofner-Agostini $M$, et al. Canadian nosocomial infection surveillance program. Morbidity, mortality, and healthcare burden of nosocomial Clostridium difficile associated diarrhea in Canadian hospitals. Infect Control Hosp Epidemiol 2002;23:137-40.

3 Johnson S, Gerding DN. Clostridium difficile-associated diarrhoea. Clin Infect Dis 1998;26:1027-36.

4 Kelly CP, LaMonte JT. Clostridium difficile infection. Annu Rev Med 1998:49:375-90.

5 Hurley BW, Nguyen CC. The spectrum of pseudomembrane enterocolitis and antibiotic-associated diarrhoea. Arch Intern Med 2002;162:2177-84.
6 Yassin SF, Young-Fadok TM, Zein NN, et al. Clostridium difficile-associated diarrhoea and colitis. Mayo Clin Proc 2001;76:725-30.

7 Hurley B, Nguyen CC. The spectrum of pseudomembranous enterocolitis and antibiotic-associated diarrhoea. Arch Intern Med 2002;162:2177-84.

8 Rolfe RD, Helebian S, Finegold SM. Bacterial interference between Clostridium difficile and normal bacterial flora. J Infect Dis 1981;143:470-5.

9 Hopkins MJ, Sharp R, Macfarlane GT. Variation in human intestinal microbiota with age. Dig Liver Dis 2002;34(supp12):S12-18.

10 Samore MH, Bettin KM, DeGirolami PC, et al. Wide diversity of Clostridium difficile types at a tertiary referral hospital. $J$ Infect Dis 1994;170:615-21.

11 Poxton IR, McCoubrey J, Blair G. The pathogenicity of Clostridium difficile. Clinical Microbiology and Infection 2001;7:421-4.

12 Johnson S, Clabots CR, Linn FV, et al. Nosocomial Clostridium difficile colonisation and disease. Lancet 1990;336:97-100.

13 Haslam SC, Ketley JM, Mitchell TJ, et al. Growth of Clostridium difficile and production of toxins $\mathrm{A}$ and $\mathrm{B}$ in complex and defined media. J Med Microbiol 1986;21:293-7.

14 Karlsson S, Dupuy B. Expression of Clostridium difficile toxins A and B and hair sigma factor TcdD is controlled by temperature. Infect Immun 2003;71:1784-93.

15 Dupuy B. Regulated transcription of Clostridium difficile toxin genes. Mol Microbiol 1998;27:107-20.

16 Fekety R. Guidelines for the diagnosis and management of Clostridium difficile-associated diarrhea and colitis. Am J Gastroenterol 1997;92:739-750.

17 Teasley DG, Gerding DN, Olson MN, et al. Prospective randomized trial of metronidazole versus vancomycin for the treatment of $C$ difficile associated diarrhoea and colitis. Lancet 1983;ii:1043-6.

18 Friedenberg F, Fernandez AF, Kaul V, et al. Intravenous metronidazole for the treatment of Clostridium difficile colitis. Dis Colon Rectum 2001;44:1176-80.

19 Robert CK, Church JM. Clostridium difficile-associated diarrhea and colitis; clinical manifestations, diagnosis and treatment. Dis Colon Rectum 1998;41:1435-49.

20 McFarland LV, Elmer GW, Surawicz CM. Breaking the cycle: treatment strategies for 163 cases of recurrent Clostridium difficile disease. Am J Gastroenterol 2002;97:1769-75.

21 Ketley JM, Haslam SC, Mitchell TJ, et al. Production and release of toxins A and B by Clostridium difficile. J Med Microbiol 1984;18:385-91.

22 Barbut F, Richard A, Hamadi K, et al. Epidemiology of recurrences or reinfections of Clostridium difficile-associated diarrhoea. J Clin Microbiol 2000;36:2386-8.

23 Gerding DN, Johnson S, Peterson LR, et al. Clostridium difficile-associated diarrhoea and colitis. Infect Control Hosp Epidemiol 1995;16:459-77.

24 Walters BA, Roberts R, Stafford R, et al. Relapse of antibiotic associated colitis: endogenous persistence of Clostridium difficile during vancomycin therapy. Gut 1983;24:206-12

25 Kreutzer EW, Milligan FD. Treatment of antibiotic associated pseudomembranous colitis. Johns Hopkins Med J 1978;143:67-72.

26 Castagliuolo I, Riegler MF, Valenick L, et al. Saccharomyces boulardii protease inhibits the effects of Clostridium difficile toxins $A$ and $B$ in human colonic mucosa. Infect Immun 1999:67:302-7.

27 Gill HS. Probiotics to enhance anti-infective defenses in the gastrointestinal tract. Best Pract Res Clin Gastroenterol 2003;17:755-73.

28 McFarland LV, Surawicz CM, Richard N, et al. A randomized placebocontrolled trial of Saccharomyces boulardii in combination with standard antibiotics for clostridium difficile disease. JAMA 1994;271:1913-18.

29 Surawicz CM, McFarland LV, Greenberg RN, et al. The search for a better treatment for recurrent Clostridium difficile disease: use of high-dose vancomycin combined with Saccharomyces boulardii. Clin Infect Dis 2000;31:1012-17.

30 MacGregor G, Smith AJ, Thakker B, et al. Yoghurt biotherapy: contraindicated in immunosuppressed patients? Postgrad Med J 2002;78:366-7.

31 Kyne L, Warny M, Qamar A, et al. Association between antibody response to toxin $A$ and protection against recurrent Clostridium difficile diarrhea. Lancet 2001;357:189-93.

32 Leung DY, Kelly CP, Boguniewicz M, et al. Treatment with intravenously administered gamma globulin of chronic relapsing colitis induced by Clostridium difficile toxin. J Pediatr 1991;118:633-7.

33 Salcedo J, Keates S, Pothoulakis C, et al. Intravenous immunoglobulin therapy for severe Clostridium difficile colitis. Gut 1997;41:366-70.

34 Beales ILP. Intravenous immunoglobulin for recurrent Clostridium difficile diarrhoea. Gut 2002;51:456.

35 Schwan A, Sjolins S, Trottenstam U, et al. Relapsing Clostridium difficile enterocolitis cured by rectal infusion with normal faeces. Scand J Infect Dis 1984;16:211-15.

36 Liacouras CA, Piccoli DA. Whole-bowel irrigation as an adjunct to the treatment of chronic, relapsing Clostridium difficile colitis. J Clin Gastroenterol 1996;22:186-9.

37 Aas J, Gessert CE, Bakken JS. Recurrent Clostridium difficile colitis: case series involving 18 patients treated with donor stool administered via a nasogastric tube. Clin Infect Dis 2003;36:580-5.

38 D'Souza A, Rajkumar C, Cooke J, et al. Probiotics in prevention of antibiotic associated diarrhea: meta-analysis. BMJ 2002;324:1361-6.

$39 \mathrm{Kim} \mathrm{KH}$. Immunisation of adult hamster against $\mathrm{C}$ dif-associated ileocecitis and transfer of protection to infant hamsters. Infect Immun 1987;55:2984-92.

40 Aboudala S, Kotloff KL, Kyne L, et al. Clostridium difficile vaccine and serum immunoglobulin $\mathrm{G}$ antibody response to toxin $\mathrm{A}$. Infect Immun 2003;71:1608-10. 